\title{
Cervical Pessary versus Expectant Management for the Prevention of Delivery Prior to 36 Weeks in Women with Placenta Previa: A Randomized Controlled Trial
}

\author{
Irene A. Stafford, MD ${ }^{1,2}$ Thomas J. Garite, MD ${ }^{3,4}$ Kimberly Maurel, MSN, CNS, RN ${ }^{4}$ \\ C. Andrew Combs, MD, PhD ${ }^{4,5}$ Kent Heyborne, MD ${ }^{6}$ Richard Porreco, MD ${ }^{7}$ Michael Nageotte, MD $^{8}$ \\ Susan Baker, MD ${ }^{9}$ Sameer Gopalani, MD ${ }^{10}$ Chi Dola, MD ${ }^{11}$ Helen How, MD ${ }^{12}$ Anita F. Das, PhD ${ }^{13}$ \\ the Obstetrix Collaborative Research Network
}

\footnotetext{
${ }^{1}$ Department of Obstetrics and Gynecology, Texas Children's Hospital, Baylor College of Medicine, Houston, Texas

${ }^{2}$ Touro Infirmary, Louisiana State University Health Science Center, New Orleans, Louisiana

3 University of California, Irvine, Orange, California

${ }^{4}$ The Center for Research, Education, Quality and Safety, Mednax, Inc., Sunrise, Florida

5 Obstetrix Medical Group, San Jose, California

${ }^{6}$ Denver Health and Hospital Authority, Denver, Colorado

${ }^{7}$ Obstetrix Medical Group of Colorado, Denver, Colorado

8 Long Beach Memorial Medical Center, Long Beach, California

${ }^{9}$ University of South Alabama Children's and Women's Hospital, Mobile, Alabama

10 Obstetrix Medical Group of Washington, Seattle, Washington

11 Tulane Lakeside Hospital for Women and Children, New Orleans, Louisiana

12 Norton Hospital, Louisville, Kentucky

${ }^{13}$ Das Consulting Group, San Francisco, California
}

Am J Perinatol Rep 2019;9:e160-e166.

Address for correspondence Irene A. Stafford, MD, Texas Children's
Hospital, Baylor College of Medicine, 6651 Main Street, 10th Suite F1020, Houston, TX 77031 (e-mail: Irene.Stafford@bcm.edu).

\begin{abstract}
Keywords

- placenta previa

- pessary

- hemorrhage

- preterm birth

Objective This multicenter randomized controlled trial compared cervical pessary $(\mathrm{CP})$ versus expectant management $(\mathrm{EM})$ in women with placenta previa between 22.0 and 32.0 in prolonging gestation until $\geq 36.0$ weeks' gestation.

Study Design This study took place from November 2016 to June 2018. Women were randomized to receive either the Bioteque $\mathrm{CP}$ or EM. The pessary was removed at $\geq 36.0$ weeks unless indicated. The primary outcome was gestational age (GA) at delivery, with secondary outcomes including need for transfusion, number and duration of antepartum admissions, type of delivery, and neonatal outcomes. A total of 140 patients were needed to show a 3-week prolongation of pregnancy in the pessary group; however, the trial was stopped early due to budgetary issues.

Results Of the 33 eligible women, 17 were enrolled. Although not statistically significant, the mean $\mathrm{GA}$ at delivery in the $\mathrm{CP}$ group was greater than women in the EM group $(36.5 \pm 1.23$ vs. $36.0 \pm 2.0 ; p=0.1673)$. The number and duration of antepartum admissions was greater in the EM group ( $2.7 \pm 0.58$ vs. $16.0 \pm 22.76$ days; $p=0.1264$ ) as well.

Conclusion Although the study was underpowered to determine the primary outcome, safety and feasibility of $\mathrm{CP}$ in pregnancies complicated with previa were demonstrated.
\end{abstract}

received

January 4, 2019

accepted

February 21, 2019
DOI https://doi.org/

10.1055/s-0039-1687871. ISSN 2157-6998.
Copyright $\odot 2019$ by Thieme Medical

Publishers, Inc., 333 Seventh Avenue, New York, NY 10001, USA Tel: +1(212) 584-4662.
License terms

(c) (i) $\ominus$ (\$) 
Placenta previa complicates $\sim 1$ in 200 pregnancies and may result in preterm birth secondary to antepartum hemorrhage. ${ }^{1-3}$ Approximately $40 \%$ of pregnant women with this condition deliver preterm, either due to bleeding, preterm labor, or to avoid further vaginal bleeding and associated morbidities. Although risk factors for placenta previa are well described and include prior uterine surgery, increased parity, smoking, and prior previa, the mechanism for the onset of clinically significant bleeding remains largely unknown. ${ }^{4-10}$ The traditional description related to the onset of vaginal bleeding in cases with placenta previa has been described as a painless phenomenon, suggesting that cervical effacement or dilation without significant uterine activity may lead to the cascade of placental separation from the lower uterine segment, resultant bleeding, further cervical change, and initiation of uterine contractions resulting in more hemorrhage. In the nonprevia patient, it is well established that cervical shortening detected by endovaginal ultrasound precedes preterm labor and delivery by several weeks. ${ }^{11-13}$ One trial evaluating the relationship between cervical length and hemorrhage in women with placenta previa has shown a threefold increased risk of hemorrhage typically leading to preterm delivery when the cervical length measured $\leq 30$ mm after 24 weeks. $^{14}$ This understanding has led to the question of whether interventions to maintain cervical length or provide support to the cervix may delay preterm delivery in women with placenta previa. Meta-analyses of trials of cerclage in women with singleton pregnancies who had a short cervix have not shown a significantly lower rate of preterm delivery overall than the rate without cerclage; however, they have shown benefit in the subgroup of women who had a previous preterm delivery. ${ }^{15-19}$ Several studies, including three randomized controlled trials, have demonstrated that cervical cerclage placement in women with placenta previa may reduce antepartum hemorrhage and prolong gestation. ${ }^{20-22}$ The Cochrane Review of Randomized Controlled Trials (Neilson, Issue 4, 2009) concluded that these trials using cervical cerclage in women with placenta previa, collectively show a relative risk (RR) of delivery at $<36$ weeks' gestation of 0.45 with cerclage, an average entry to delivery prolongation RR of 0.35 for an interval of $<6$ weeks with cerclage, and a RR of blood transfusion of 0.59 for the cerclage group. Cerclage placement in these studies was performed after the sentinel bleed during the third trimester, making comparisons and estimates of benefit challenging. However, few clinicians have adopted this approach presumably due to fear over the risks of surgically placing the suture near the site of placental implantation.

An alternative less invasive approach to the prevention of preterm birth involves transvaginal placement of a silicone pessary around the cervix with the aim of providing support for the cervix and lower uterine contents using the posterior vagina and sacrum. ${ }^{23}$ Results have been contradictory in women with a shortened cervix with a singleton gestation. In one trial, the rate of preterm birth was significantly lower with a pessary than with no pessary (6 vs. $27 \%$ ), ${ }^{24}$ but in a second smaller trial, there was no significant effect (9.4 and $5.5 \%$, respectively). ${ }^{25}$ The largest randomized controlled trial to date demonstrated no difference in preterm birth between women who did and did not receive cervical pessary (CP) placed between $20^{0 / 7}$ and $23^{6 / 7}$ weeks. ${ }^{26,27}$ Similarly, when the conflicting results of pessary trials were compiled, pessary use was not associated with a reduction in preterm birth or neonatal death in unselected twins. ${ }^{27-31}$ Since there are no interventions other than possible cervical cerclage that are known to reduce the potentially devastating risk of premature delivery and maternal hemorrhage in the setting of placenta previa, the need for a clinically acceptable and reasonably safe intervention is apparent. The CP commonly used in women's health might be as efficacious as cerclage in preventing hemorrhage-related preterm birth in this cohort of women. A recent randomized trial using a dome silicone pessary with vaginal progesterone in women with previa demonstrated that women in the pessary group were threefold less likely to experience vaginal bleeding prior to delivery and were less likely to deliver prior to 34 weeks' gestation. ${ }^{32}$

The purpose of this study is to perform a multicenter randomized trial comparing the role of a $\mathrm{CP}$ versus expectant management $(E M)$ in women with placenta previa between $22^{0 / 7}$ and $32^{0 / 7}$ in prolonging gestation until $\geq 36$ weeks. Secondary outcomes include an assessment of duration of antepartum admission(s), total blood loss, gestational age (GA) at delivery, type of cesarean delivery, neonatal intensive care unit admission, and a composite neonatal outcome.

\section{Methods}

This was an unblinded multicenter randomized controlled trial of CP versus EM in women with a singleton pregnancy and a complete placenta previa ( $\geq 10 \mathrm{~mm}$ over os) identified between $22^{0 / 7}$ and $32^{0 / 7}$ weeks' gestation involving 9 principal investigators and 10 sites in the United States (Baylor College of Medicine/Texas Children's Hospital, Houston, TX; Touro Infirmary, New Orleans, LA; Tulane Lakeside Hospital for Women and Children, New Orleans, LA; Good Samaritan Hospital, San Jose, CA; Denver Health and Hospital Authority, Denver, CO; Presbyterian St Luke's Hospital, Denver, CO; Long Beach Memorial Medical Center, Long Beach, CA; University of South Alabama Children's and Women's Hospital, Mobile AL; Swedish Medical Center, Seattle, WA; and Norton Hospital, Louisville, KY) between November 2016 and June 2018. The study was approved by the Institutional Review Boards at each site and was prospectively registered in ClinicalTrials.gov (NCT01996345).

Patients presenting for routine or any other indicated sonographic evaluation at each center and found to have a complete placenta previa were initially screened and offered enrollment if they met inclusion criteria. These included age $>18$ years old, GA between $22^{0 / 7}$ and $32^{0 / 7}$ weeks' gestation, intact membranes, no allergies to material in pessary, plan to deliver at the principal investigator's hospital, and provided informed consent. Exclusion criteria were fetal infections, hydrops, multiple gestation, active preterm labor, rupture of membranes, active vaginal bleeding, cerclage, known uterine anomaly, major fetal anomalies, or demise. Eligible women were randomized to receive either 
the Bioteque (Bioteque America Inc., San Jose, CA) cup CP or EM with no pessary in a 1:1 ratio using the MDXPLORE computer generated randomization table unique to each site, stratified by GA groups $22^{0 / 7}$ to $26^{6 / 7}$ or $27^{0 / 7}$ to $32^{0 / 7}$. Women in the pessary group underwent pessary placement within 72 hours after randomization. Patients, clinicians, and research personnel were blinded to the group assignment before enrollment. Cervical cup pessaries made with flexible silicone were purchased from the distributor (Bioteque America Inc.) While the pessary used in this study is an Food and Drug Administration approved device for recurrent miscarriage in pregnancy and pelvic support in women and carries a class II devised classification, the Institutional Review Boards required a separate Investigational New Device approval for this specific indication which was obtained (21 CFR 884.3575/K092981). The research team providers placing the cervical pessaries received educational instruction on selecting the appropriate size and placement of the device prior to initiation of the trial. A speculum examination was performed to inspect the cervix for any pathology and to assist in determining the appropriate pessary size. The pessary was then inserted vaginally with the woman in the recumbent position and placed upward around the cervix. Once proper position and patient comfort were assured, the patient was discharged with instructions to keep the pessary in at all times and return for any concerns until planned pessary removal at 36 weeks' gestation unless otherwise indicated. Cervical length measurements were performed at the discretion of the managing physician.
Women in the EM group received the same obstetrical care as those in the pessary group. Follow-up visits for ultrasound assessment of fetal growth were scheduled at the discretion of the managing physician with a sonographic evaluation to confirm placental location between 34 and 36 weeks for delivery planning. The participants randomized to the pessary were informed of all precautions related to pessary use including the possibility of an increase in vaginal discharge and pressure. At each follow-up visit, all participants in both arms of the study were asked to complete a side effect questionnaire for which the results were recorded. Women reporting more vaginal discharge than what is typically expected with pessary use were examined by a doctor for evidence of infection and antibiotic therapy was given without removal of the pessary if indicated. The $\mathrm{CP}$ was removed at 36 weeks' gestation in asymptomatic patients or earlier if placenta previa had resolved or the patient had delivered. Otherwise, earlier removal of the pessary was undertaken upon patient request. Tocolytics and antenatal corticosteroids were administered at the discretion of the provider.

The primary outcome for this study was rate of delivery prior to 36 weeks' gestation. Secondary outcomes included need for packed red blood cells or product replacement, number and duration of antepartum admissions, type of cesarean delivery, fetal demise, and neonatal outcomes including birth weight, neonatal intensive care admission, and cord $\mathrm{pH}$ less than 7.1 along with a composite neonatal morbidity including any of the following: respiratory distress syndrome, bronchopulmonary dysplasia, severe intraventricular hemorrhage, periventricular

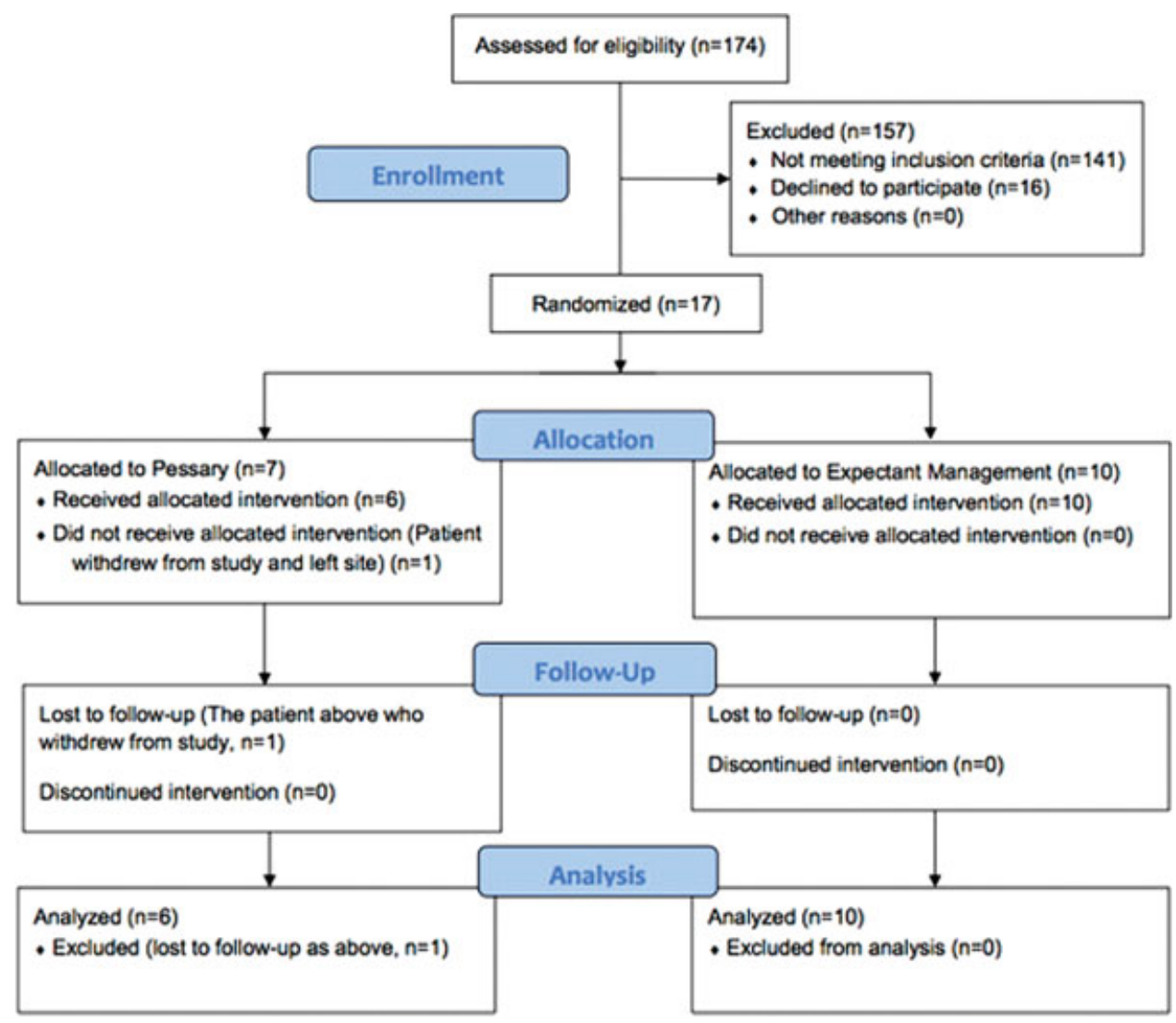

Fig. 1 Flow diagram of the study population. 
leukomalacia, proven sepsis, necrotizing enterocolitis, or neonatal death. All maternal data up to 28 days postpartum and neonatal data up to 60 days of life were recorded. Any adverse reactions or effects of the pessary were also recorded.

All women were analyzed in the group to which they were randomized. Descriptive statistics of the primary outcome, GA at delivery, were calculated for the pessary and EM groups. Differences between the intervention groups in the intent-to-treat population were tested for statistical significance using a van Elteren's test (stratified for GA at randomization). Descriptive statistics were provided for secondary outcomes.

The sample size calculation was based on the study by Arias ${ }^{20}$ in which a mean GA of delivery of 32 weeks' gestation was found in the control subjects and 35 weeks' gestation in women with a cerclage. Both the studies by Arias ${ }^{20}$ and the Cobo et $\mathrm{al}^{21}$ reported a standard deviation of $\sim 3$ weeks for $\mathrm{GA}$ at delivery. Since these were both small studies, a standard deviation of 6 weeks was used in the sample size calculation. For $80 \%$ power and two-sided $\alpha=0.049$, we calculated that a total of 140 patients would be needed to show a 3-week difference in the mean GA of delivery (based on a Wilcoxon's rank-sum test). We anticipated the study to take 4 years with all 10 sites involved.

The trial was stopped early before completion secondary to slow enrollment and withdrawal of financial support by the sponsor due to budgetary issues and company reorganization.

\section{Results}

Of the 174 women screened during the study period from all 10 centers, 33 met criteria and 17 agreed to enroll in the study. One patient withdrew (randomized to pessary arm) prior to placement due to change in location ( - Fig. 1). The characteristics of the enrolled patients are shown in - Table 1. Although the sample size is too small to determine significant differences, the mean GA at randomization was slightly earlier in the pessary group compared with EM group $(25.5 \pm 2.28$ vs. $28.8 \pm 2.19)$. There was no difference in the number of women with prior preterm birth and 17 hydroxyprogesterone caproate use between both groups.

There was no significant difference in the mean GA at delivery between the pessary and EM groups; however, the study was underpowered to allow a conclusion of no difference (-Table 2). The mean GA at delivery of women in the pessary group and the EM group was 36.5 and 36.0 weeks, respectively $(p$-value $=0.1673)$. Women in the pessary group had fewer admissions for bleeding during the antepartum period. There were three antepartum admissions in the pessary group with a median duration of 3 days compared with the eight antepartum admissions in the EM group with a median duration of 5 days. Of note, there was one EM subject who had a 68-day duration of antenatal admission. The mean GA of scheduled delivery in the pessary and EM groups was 37.2and 36.2 weeks, respectively. Although both groups had equal numbers of cesarean deliveries for urgent indications, one patient in the EM group underwent emergent/STAT cesarean delivery at 33.2 weeks' gestation for hemorrhage (-Table 3).
Table 1 Baseline characteristics

\begin{tabular}{|c|c|c|}
\hline & $\begin{array}{l}\text { Pessary } \\
(N=7)\end{array}$ & $\begin{array}{l}\text { Expectant } \\
\text { management } \\
(N=10)\end{array}$ \\
\hline \multicolumn{3}{|l|}{ Age $(y)$} \\
\hline Mean (std) & $34.1(4.45)$ & $33.2(5.45)$ \\
\hline Min, max & 29,42 & 24,42 \\
\hline \multicolumn{3}{|l|}{ Weight (lb) } \\
\hline Mean (std) & $167.1(17.98)$ & $157.4(27.45)$ \\
\hline Min, max & 147,187 & 124,203 \\
\hline \multicolumn{3}{|l|}{ Race, $n(\%)$} \\
\hline Asian & $1(14.3)$ & 0 \\
\hline Black & $4(57.1)$ & $2(20.0)$ \\
\hline White & $1(14.3)$ & $7(70.0)$ \\
\hline Other & $1(14.3)$ & $1(10.0)$ \\
\hline \multicolumn{3}{|l|}{ Marital status, $n(\%)$} \\
\hline $\begin{array}{l}\text { Married/living } \\
\text { with partner }\end{array}$ & $3(42.9)$ & $8(80.0)$ \\
\hline Single/widowed & $4(57.1)$ & $2(20.0)$ \\
\hline Nulliparous, $n$ (\%) & $2(28.6)$ & $3(30.0)$ \\
\hline Prior PTB, $n(\%)$ & $2(28.6)$ & $3(30.0)$ \\
\hline \multicolumn{3}{|c|}{ GA at randomization (wk) } \\
\hline Mean (std) & $25.5(2.28)$ & $28.8(2.19)$ \\
\hline Min, max & $22.0,28.43$ & $23.43,31.14$ \\
\hline \multicolumn{3}{|c|}{ GA at randomization, $n(\%)$} \\
\hline $22^{0 / 7}-26^{6 / 7}$ & $5(71.4)$ & $1(10.0)$ \\
\hline $27^{0 / 7}-32^{0 / 7}$ & $2(28.6)$ & $9(90.0)$ \\
\hline
\end{tabular}

Abbreviations GA, gestational age, PTB, preterm birth; std, standard deviation.

With respect to the neonatal outcomes, the mean birth weight was greater in the pessary group $(3,009 \pm 464$ vs. $2,609 \pm 389 \mathrm{~g})(p$-value $=0.03)$ most likely due to the later GA at delivery of women randomized to the pessary (-Table 4). Rates of adverse neonatal outcomes including neonatal death were similar between the pessary and EM groups. Reported vaginal discharge or pelvic discomforts at the randomization visit and with follow-up visits were similar in the two groups, with only one woman in each group reporting an increase in vaginal discharge, of which neither required antibiotic therapy after evaluation.

\section{Discussion}

While this trial failed to demonstrate a difference in GA at delivery between the $\mathrm{CP}$ and EM groups, enrollment was discontinued prior to reaching the number of women required to adequately examine the primary and secondary outcomes. Enrollment was challenging due to slow enrollment, mainly related to patient reluctance to participate. An additional 7 years would be required to achieve the number of women required to complete the study according to our power 
Table 2 Primary and secondary outcomes

\begin{tabular}{|c|c|c|}
\hline & $\begin{array}{l}\text { Pessary } \\
(N=7)\end{array}$ & $\begin{array}{l}\text { Expectant } \\
\text { management } \\
(N=10)\end{array}$ \\
\hline \multicolumn{3}{|l|}{ GA at delivery (wk) } \\
\hline$N$ & 6 & 10 \\
\hline Mean (std) & $36.5(1.23)$ & $36.0(2.00)^{\mathrm{a}}$ \\
\hline Min, max & $34.3,37.7$ & $33.3,39.1$ \\
\hline$\%$ Delivered $<36$ wk & $1(16.7)$ & $4(40.0)$ \\
\hline \multicolumn{3}{|c|}{ Need for packed red blood cells or hematologic products } \\
\hline Antepartum & 0 & $1(10.0)$ \\
\hline $\begin{array}{l}\text { Hospital leading } \\
\text { to delivery }\end{array}$ & $2(28.6)$ & 0 \\
\hline Postpartum & $1(14.3)$ & 0 \\
\hline \multicolumn{3}{|c|}{ Number of antepartum admissions } \\
\hline 0 & $5(71.4)$ & $4(40.0)$ \\
\hline 1 & $1(14.3)$ & $4(40.0)$ \\
\hline 2 & $1(14.3)$ & $2(20.0)$ \\
\hline \multicolumn{3}{|c|}{ Duration of antepartum admissions ${ }^{\mathrm{b}}$} \\
\hline$N$ (number of admissions) & 3 & 8 \\
\hline Mean (std) & $2.7(0.58)$ & $16.0(22.76)$ \\
\hline Median & 3 & 5 \\
\hline Min, max & 2,3 & 2,68 \\
\hline \multicolumn{3}{|l|}{ Type of delivery } \\
\hline SVD & 0 & $1(10.0)$ \\
\hline Primary $\mathrm{C} / \mathrm{S}$ & $5(71.4)$ & $6(60.0)$ \\
\hline Repeat C/S & $1(14.3)$ & $3(30.0)$ \\
\hline Unknown & $1(14.3)$ & 0 \\
\hline Fetal death & 0 & 0 \\
\hline
\end{tabular}

Abbreviations: $C / S$, cesarean section; $G A$, gestational age, std, standard deviation; SVD, spontaneous vaginal delivery.

${ }^{\mathrm{a}} p$-Value $=0.1673$ based on a van Elteren's test stratified for GA at randomization.

${ }^{\mathrm{b}} p$-Value $=0.1264$ based on Wilcoxon's sign-rank test ( $N$ too small to stratify by $G A$ at randomization).
Table 4 Secondary neonatal outcomes

\begin{tabular}{|c|c|c|}
\hline & $\begin{array}{l}\text { Pessary } \\
(N=7)\end{array}$ & $\begin{array}{l}\text { Expectant } \\
\text { management } \\
(N=10)\end{array}$ \\
\hline \multicolumn{3}{|l|}{ Birth weight $(\mathrm{g})^{\mathrm{a}}$} \\
\hline$N$ & 6 & 10 \\
\hline Mean (std) & $3,008.7(464.21)$ & 2,609.4 (388.64) \\
\hline Min, max & $2,390,3,630$ & $2,010,3,120$ \\
\hline Neonatal death & 0 & 0 \\
\hline $\begin{array}{l}\text { Composite } \\
\text { morbidity, } n(\%)^{\mathrm{b}}\end{array}$ & 0 & $1(10.0)$ \\
\hline RDS & 0 & $1(10.0)$ \\
\hline BPD & 0 & 0 \\
\hline Severe IVH & 0 & 0 \\
\hline PVL & 0 & 0 \\
\hline Proven sepsis & 0 & 0 \\
\hline NEC & 0 & 0 \\
\hline Perinatal death & 0 & 0 \\
\hline Apgar $<3$ at 5 min & 0 & 0 \\
\hline $\begin{array}{l}\text { NICU/IMC/CCU } \\
\text { admission }^{b}\end{array}$ & $1(14.3)$ & $4(10.0)$ \\
\hline Cord $\mathrm{pH}<7.1^{\mathrm{c}}$ & 0 & 0 \\
\hline
\end{tabular}

Abbreviations: BPD, bronchopulmonary dysplasia; CCU, cardiac care unit; IMC, intermediate care; IVH, intraventricular hemorrhage; NEC, necrotizing enterocolitis; NICU, neonatal intensive care unit; PVL, periventricular leukomalacia; RDS, respiratory distress syndrome. ${ }^{\mathrm{a}} p$-Value $=0.0320$ based on a van Elteren's test stratified for GA at randomization.

${ }^{\mathrm{b}}$ One unknown in each group.

'Data available for five neonates.

analysis. Previous studies have demonstrated that the placement of cervical cerclage has demonstrated benefit for women with placenta previa. ${ }^{20-22}$ However, the invasive nature of this technique has prompted providers to consider alternative options like the $\mathrm{CP}$ as it remains easy to place, requires no anesthesia or operating room, and is considered less risky, especially for women with placenta previa. ${ }^{23}$ Although earlier

Table 3 GA at delivery by type of cesarean delivery $(C / S)$ with pessary/expectant management

\begin{tabular}{|l|l|l|l|l|l|l|}
\hline \multirow{2}{*}{} & \multicolumn{2}{|l|}{ Pessary } & \multicolumn{2}{l|}{ Expectant management } \\
\cline { 2 - 7 } & $\begin{array}{l}\text { C/S (emergent - } \\
\text { Stat/crash) }\end{array}$ & $\begin{array}{l}\text { C/S (emergent-Stat/ } \\
\text { crash + urgent/ } \\
\text { not emergent) }\end{array}$ & $\begin{array}{l}\text { C/S (routine/ } \\
\text { scheduled) }\end{array}$ & $\begin{array}{l}\text { C/S (emergent - } \\
\text { Stat/crash) }\end{array}$ & $\begin{array}{l}\text { CS (emergent-Stat/ } \\
\text { crash + urgent/ } \\
\text { not emergent) }\end{array}$ & $\begin{array}{l}\text { C/S (routine/ } \\
\text { scheduled) }\end{array}$ \\
\hline GA at delivery (wk) & 2 & 4 & 1 & 2 & 7 \\
\hline N & 0 & 35.14 & 37.21 & 33.29 & 35.14 & 36.27 \\
\hline Mean & 1.212 & 0.378 & NA & 1.212 & 1.581 \\
\hline Std & 34.29 & 36.86 & 33.29 & 34.29 & 33.43 \\
\hline Min & 36.00 & 37.71 & 33.29 & 36.00 & 38.14 \\
\hline Max & & & & & \\
\hline
\end{tabular}

Abbreviation: C/S, cesarean section; GA, gestational age; Std, standard deviation. 
data had reported prolongation of pregnancy with $\mathrm{CP}$ in certain risk groups, more recent studies suggest that $\mathrm{CP}$ does not prevent preterm birth in women with a sonographically identified short cervix or improve perinatal outcomes for such patients. ${ }^{26-28,30}$ Our findings are similar to the single previous study evaluating the role of $\mathrm{CP}$ as a preterm birth prevention strategy, in that cervical cup pessary placement in women with a complete previa is associated with a reduction in admissions for vaginal bleeding leading to delivery. ${ }^{32}$ In our study, the number of antepartum admissions for bleeding was twofold higher in women randomized to the EM group.

This trial is the first multicenter randomized trial evaluating the role of a silicone cup pessary in women with placenta previa. Although the largest limitation remains that it is an underpowered study closed prior to full enrollment, it demonstrates several important points related to the pessary for this population. The most important result given the limited number of patients studied was that the pessary was tolerated by more than $95 \%$ of patients, with no adverse effects or serious side effects recorded. Providers were able to place and remove the pessary without consequence. In addition, the findings of this study as well as previous observations that premature cervical shortening associated with bleeding in placenta previa may suggest a potential benefit with minimal risk, therefore, justifying an appropriately powered randomized controlled trial to evaluate the role of $\mathrm{CP}$ in women with placenta previa in the future.

\section{Conflict of Interest}

Dr. Das reports personal fees from Obstetrix Medical Group, during the conduct of the study; personal fees from Hologic, outside the submitted work. Dr. Garite reports other from Mednax, Inc., during the conduct of the study, outside the submitted work.

\section{References}

1 Silver RM. Abnormal placentation: placenta previa, vasa previa, and placenta accreta. Obstet Gynecol 2015;126(03):654-668

2 Iyasu S, Saftlas AK, Rowley DL, Koonin LM, Lawson HW, Atrash HK. The epidemiology of placenta previa in the United States, 1979 through 1987. Am J Obstet Gynecol 1993;168(05):1424-1429

3 Cresswell JA, Ronsmans C, Calvert C, Filippi V. Prevalence of placenta praevia by world region: a systematic review and meta-analysis. Trop Med Int Health 2013;18(06):712-724

4 Getahun D, Oyelese Y, Salihu HM, Ananth CV. Previous cesarean delivery and risks of placenta previa and placental abruption. Obstet Gynecol 2006;107(04):771-778

5 Ananth CV, Smulian JC, Vintzileos AM. The association of placenta previa with history of cesarean delivery and abortion: a metaanalysis. Am J Obstet Gynecol 1997;177(05):1071-1078

6 Ananth CV, Wilcox AJ, Savitz DA, Bowes WA Jr, Luther ER. Effect of maternal age and parity on the risk of uteroplacental bleeding disorders in pregnancy. Obstet Gynecol 1996;88(4 Pt 1):511-516

7 Macones GA, Sehdev HM, Parry S, Morgan MA, Berlin JA. The association between maternal cocaine use and placenta previa. Am J Obstet Gynecol 1997;177(05):1097-1100

8 Ananth CV, Demissie K, Smulian JC, Vintzileos AM. Placenta previa in singleton and twin births in the United States, 1989 through 1998: a comparison of risk factor profiles and associated conditions. Am J Obstet Gynecol 2003;188(01):275-281
9 Crane JM, Van den Hof MC, Dodds L, Armson BA, Liston R. Maternal complications with placenta previa. Am J Perinatol 2000;17(02):101-105

10 Grobman WA, Gersnoviez R, Landon MB, et al; National Institute of Child Health and Human Development (NICHD) Maternal-Fetal Medicine Units (MFMU) Network. Pregnancy outcomes for women with placenta previa in relation to the number of prior cesarean deliveries. Obstet Gynecol 2007;110(06):1249-1255

11 Iams JD, Goldenberg RL, Meis PJ, et al; National Institute of Child Health and Human Development Maternal Fetal Medicine Unit Network. The length of the cervix and the risk of spontaneous premature delivery. N Engl J Med 1996;334(09):567-572

12 Goldenberg RL, Iams JD, Das A, et al; National Institute of Child Health and Human Development Maternal-Fetal Medicine Units Network. The Preterm Prediction Study: sequential cervical length and fetal fibronectin testing for the prediction of spontaneous preterm birth. Am J Obstet Gynecol 2000;182(03): 636-643

13 Andrews WW, Copper R, Hauth JC, Goldenberg RL, Neely C, Dubard M. Second-trimester cervical ultrasound: associations with increased risk for recurrent early spontaneous delivery. Obstet Gynecol 2000;95(02):222-226

14 Stafford IA, Dashe JS, Shivvers SA, Alexander JM, McIntire DD, Leveno KJ. Ultrasonographic cervical length and risk of hemorrhage in pregnancies with placenta previa. Obstet Gynecol 2010; 116(03):595-600

15 Berghella V, Odibo AO, To MS, Rust OA, Althuisius SM. Cerclage for short cervix on ultrasonography: meta-analysis of trials using individual patient-level data. Obstet Gynecol 2005;106(01): 181-189

16 Alfirevic Z, Stampalija T, Medley N. Cervical stitch (cerclage) for preventing preterm birth in singleton pregnancy. Cochrane Database Syst Rev 2017;6:CD008991

17 Enakpene CA, DiGiovanni L, Jones TN, Marshalla M, Mastrogiannis $D$, Della Torre M. Cervical cerclage for singleton pregnant patients on vaginal progesterone with progressive cervical shortening. Am J Obstet Gynecol 2018;219(04):397.e1-397.e10

18 Liu Y, Ke Z, Liao W, et al. Pregnancy outcomes and superiorities of prophylactic cervical cerclage and therapeutic cervical cerclage in cervical insufficiency pregnant women. Arch Gynecol Obstet 2018;297(06):1503-1508

19 Berghella V, Ciardulli A, Rust OA, et al. Cerclage for sonographic short cervix in singleton gestations without prior spontaneous preterm birth: systematic review and meta-analysis of randomized controlled trials using individual patient-level data. Ultrasound Obstet Gynecol 2017;50(05):569-577

20 Arias F. Cervical cerclage for the temporary treatment of patients with placenta previa. Obstet Gynecol 1988;71(04):545-548

21 Cobo E, Conde-Agudelo A, Delgado J, Canaval H, Congote A. Cervical cerclage: an alternative for the management of placenta previa? Am J Obstet Gynecol 1998;179(01):122-125

22 Jaswal A, Manaktala U, Sharma JB. Cervical cerclage in expectant management of placenta previa. Int J Gynaecol Obstet 2006;93 (01):51-52

23 Arabin B, Alfirevic Z. Cervical pessaries for prevention of spontaneous preterm birth: past, present and future. Ultrasound Obstet Gynecol 2013;42(04):390-399

24 Goya M, Pratcorona L, Merced C, et al; Pesario Cervical para Evitar Prematuridad (PECEP) Trial Group. Cervical pessary in pregnant women with a short cervix (PECEP): an open-label randomised controlled trial. Lancet 2012;379(9828):1800-1806

25 Hui SY, Chor CM, Lau TK, Lao TT, Leung TY. Cerclage pessary for preventing preterm birth in women with a singleton pregnancy and a short cervix at 20 to 24 weeks: a randomized controlled trial. Am J Perinatol 2013;30(04):283-288

26 Nicolaides KH, Syngelaki A, Poon LC, et al. A randomized trial of a cervical pessary to prevent preterm singleton birth. $\mathrm{N}$ Engl J Med 2016;374(11):1044-1052 
e166 Previa-Pessary Stafford et al.

27 Saccone G, Ciardulli A, Xodo S, et al. Cervical pessary for preventing preterm birth in twin pregnancies with short cervical length: a systematic review and meta-analysis. J Matern Fetal Neonatal Med 2017;30(24):2918-2925

28 Nicolaides KH, Syngelaki A, Poon LC, et al. Cervical pessary placement for prevention of preterm birth in unselected twin pregnancies: a randomized controlled trial. Am J Obstet Gynecol 2016;214(01):3.e1-3.e9

29 Jarde A, Lutsiv O, Park CK, et al. Preterm birth prevention in twin pregnancies with progesterone, pessary, or cerclage: a systematic review and meta-analysis. BJOG 2017;124(08):1163-1173
30 Berghella V, Dugoff L, Ludmir J. Prevention of preterm birth with pessary in twins (PoPPT): a randomized controlled trial. Ultrasound Obstet Gynecol 2017;49(05):567-572

31 Saccone G, Ciardulli A, Xodo S, et al. Cervical pessary for preventing preterm birth in singleton pregnancies with short cervical length: a systematic review and meta-analysis. J Ultrasound Med 2017;36(08):1535-1543

32 Barinov SV, Shamina IV, Di Renzo GC, et al. The role of cervical pessary and progesterone therapy in the phenomenon of placenta previa migration. J Matern Fetal Neonatal Med 2018;•••:1-11 